\title{
Research on Local College Teaching Supervision Status and Team Construction
}

\author{
Hongjun Lian, Hongrui Zhu, Zhongwei Li, Shuguo Zhao \\ North China University of science and technology, Tangshan Hebei, 063009, China
}

Keywords: Local college, Teaching supervision, Team construction

\begin{abstract}
Aiming that currently, for local college teaching supervision, system is not perfect, methods are simple and teaching supervision teams are aging, insufficient and their professional quality remains to be improved and other problems, this paper proposes constructive countermeasures, including perfecting teaching supervision system, integrating supervision and service, and strengthening supervision team specialized construction, to promote standardized, specialized construction of local college teaching supervision team, and improve teaching quality.
\end{abstract}

\section{Introduction}

Teaching supervision is a general name for a series of activities such as teaching quality supervision, control, evaluation, guidance by colleges, and currently, the main work is to inspect and supervise whole teaching process and teaching management, to grasp the situation, sum up experience, identify problems and timely analyze and give guidance to ensure improvement of teaching quality.

\section{Status and problems of local college teaching supervision}

\section{System security and operation mechanism of teaching supervision}

With the continuous deepening reform of higher education, college teaching quality competition intensifies. To improve core competitiveness, many colleges establish school-level and college-level (department) teaching supervision systems. In general situation, these supervision organizations carry out work under the leadership of Vice President in charge of teaching, according to the national educational policy and school rules and regulations, act as expert face campus teaching and learning and teaching process, supervise, inspect, evaluate, and guide various factors affecting the quality of college teaching. Most colleges develop special teaching supervision documents to ensure there are teaching supervision rules to follow, such as the "Beijing University of Science and Technology Undergraduate Education Steering Group Work Management Approaches", " Guangdong University of Technology Teaching Supervision Work Regulations", "Hebei United University Teaching Steering Committee Implementation Details" and so on, which define teaching supervision function orientation, responsibilities and staff. For example, in terms of hiring supervision staff, Hebei United University requires hiring professors who are rigorous, act as role model, and have high academic level, rich teaching experience, and certain influence. Ratio of retired professors and on-duty professors is 2: 1 , to strongly guarantee effective implementation of teaching supervision.

Most colleges have two teaching supervision mechanism modes, one of which is the independent teaching supervision department under the direct leadership of president or vice president in charge of teaching work, parallel with teaching affairs office; the other one is affiliated to teaching affairs office or college research institute, or one office or supervision group subordinated to teaching affairs office. The second mode accounts for a large proportion. Supervision group can access to information conveniently and timely, but lack its own organization operating mechanism and rules, and lack effective system and mechanism guarantee. The positioning of teaching supervision is not clear, job responsibilities are also not clear, and the supervision effect is not obvious.

Work responsibilities and methods of teaching supervision

After survey analysis, we found that the effect of teaching supervision carried out by many local colleges is very good, for example, teaching supervisors will often randomly listen to lessons in 
classroom, timely feedback issues to the school, and school will timely take measures to resolve problems, to ensure normal operation of the daily teaching order; teaching supervisors check the teaching of various teaching, to promote two-level college teaching management to constantly improve and perfect; through classroom teaching supervision and special training activities, teaching supervisory staff promote young teachers reach teaching standard fast and well, and improve faculty level; supervisors are involved in quality courses, construction and evaluation, to promote school curriculum system, teaching means and methods reform; supervisory staff are involved in teaching evaluation, and professional certification, etc., which promotes the construction of professional subjects, to continuously upgrade school teaching quality and level.

Some local colleges simply understand that teaching supervision is supervision and inspection, and specific job is to help school collect information, make evaluation, report results, pay too much attention to check but less to guidance, pay too much attention to figure out problems but less to solve problems, and supervision work remains in the "fault-finding" of stage. For example, in some colleges, supervisors just listen to lessons in classroom for several times and then simply make evaluation on classroom teaching quality. And evaluation results are related with titles, appraise, and assessment, resulting in that functions of teaching inspection are not fully exploited, and teachers are easy to produce hostile attitude toward supervision and misunderstanding, and become rebellious, making supervision work difficult to achieve real results.

\section{Status and problems of local college teaching supervision team construction}

Zhang Lan, Sun Yujie, Ma Shunlin, Ling Feifei, Fu Liqin, Li Jicheng, Zhang Xiaoming, etc. think that construction of educational supervision team has some problems, including age structure, professional structure, occupational structure, gender and ethnic structure are not reasonable, the implementation of the relevant treatment is not in place, quality is poor and academic ability is relatively weak. Zhang Qingchuan, Huang Wei and others believe that colleges are not clearly aware of status and role of education supervision, some regard the education supervision institutions as a "transit station for cadres", supervision team officialization is serious, guidance is ineffective, and it is difficult to improve the quality of supervision; and supervisory staff working conditions are poor. Sun Yujie, Li Shuaijun, Li Delong and others believe supervision qualification system is imperfect, education and training capacity is limited, supervisors are more administrative than professional, and educational, academic and qualification requirements of educational supervision team are relatively low, and their status is not high. Yu Hui believes that currently, our education supervisors are still in the infancy stage of professional formation, and we should strengthen specialization construction. After survey and research on the status of local college teaching supervision, we found that there are main problems as follows regarding to local college teaching supervision team.

\section{Aging teaching supervision team and single structure}

Currently, local college teaching supervision institutions setting and staff composition have several modes, and there exists a certain arbitrariness. For example, some college teaching supervisors are acted by serving staff, some all by outside personnel, some all by retirees, and some by serving personnel as well as retirees. Most college teaching supervisors are composed of retired leaders, experts and serving staff. The survey on supervision member age structure of 10 local colleges shows that, teaching supervision team is aging seriously, and age structure is irrational (see Table 1).

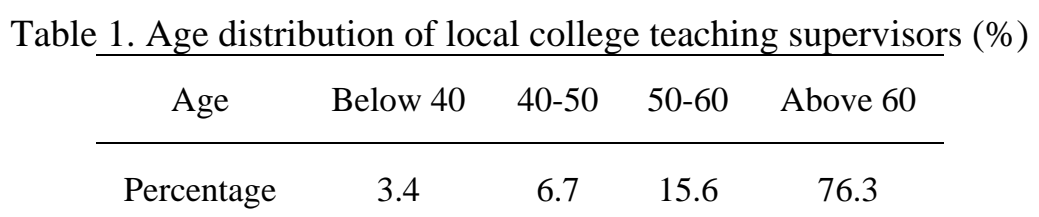

Colleges hire more than $70 \%$ of old retired teachers as supervisors, with a wealth of teaching experience, higher prestige, and enough time and energy for supervision work, which plays a significant role for a certain period, but aging of teaching supervision team also affects its further development. 
First, with the rapid development of modern information technology and knowledge, new teaching ideas, new policies and information technologies emerge continuously, education reform speeds up in varying degrees in terms of efforts, depth and breadth, so old supervisors are difficult to be in a short time familiar with or adapt to new situations, new problems and new educational philosophy, and cannot keep pace with the times in terms of guiding teaching reform, exerting teachers' potential, and other aspects; second, teaching supervision is an important and hard work, therefore, stamina and energy become one of main factors affecting supervision; third, as continuous improvement of teaching supervision system, supervising work needs to be more standardized, scientific, and technical, and supervision work relying on the experience and reputation cannot meet the development requirements of modern colleges.

\section{Insufficient teaching supervision team personnel allocation}

Local college supervision team institution remains the traditional mode. Retired teachers account for a large proportion, and there are about 10-20 persons in general. But now the development scale of colleges over the years are dramatic, including tens of thousands of students, and thousands of teachers. Current teaching supervision allocation cannot fully reflect the role of supervision. Take Hebei United University for example, now the school has 2058 full-time teachers, but the number of teachers who actually participated in supervision is just 25, and the ratio of supervisory staff and teachers is one to eighty-two. If define the scope of supervision in classroom teaching, each supervisor per week listen 10 lessons, and it needs to complete two times of classroom supervision for the related teacher during the whole semester, but based on just 1-2 times of classroom supervision in one semester, it is not enough to help some young teachers improve their teaching basic skills. At the same time, teaching supervisors also participate in paper check, graduation design (thesis) check, teaching reform project assessment, teaching individual awards evaluation, etc., thus supervisors' allocation is clearly insufficient.

\section{Narrow teaching supervision content}

Improving teaching quality is a systematic project, covering school educational positioning, talents training positioning, professional setting and optimization, course construction and reform, teaching staff construction, teaching management, learning management and other aspects. Standardized teaching supervision work includes "teaching supervision ","learning supervision" and "management supervision", but in the specific supervision work, most local college put emphasis on supervision to teaching quality, theoretical teaching, teaching order and teachers, and ignore supervision to other teaching processes, practice teaching, talents training program, syllabus and curriculum setting and optimization, and students' learning activities, teaching management work and so on.

\section{Professional quality of supervisors remains to be improved}

Retirees-oriented teaching supervision team has strong sense of responsibility, rich teaching and management experience and a certain reputation in their professional field. But professional structure and knowledge structure of supervision team is unreasonable, and it is difficult to cover all types of professions. In order to meet the needs of social and economic development and their own survival, colleges add new professions adapting to socio-economic development, and set up corresponding new courses. It is difficult for most colleges to find retirees with relevant professional background as teaching supervisor. Appearance of new teaching means and methods, such as resource sharing lesson and "MOOC" gives supervision a serious challenge. The supervision concept, vocational spirit, professional knowledge, and professional competence of supervisors keep a certain distance between modern university requirements and remain in urgent need of improvement in learning and practice

\section{Some suggestions on local college teaching supervision work}

\section{Construct sound supervision rules system}

Determine reasonable supervision mode

With the launching of new round of college undergraduate teaching conformity assessment, the school should put more emphasis on promoting the improvement of teaching quality, based on problems identification, by the way of teaching reform, reposition teaching supervision work, and 
reconstruct school-level and college-level supervision management organization combined with undergraduate teaching conformity assessment; set up supervision group in second-level schools, teaching supervision work focus moves downward, to further strengthen quality self-monitoring functions of all schools, fully mobilize the enthusiasm of the secondary schools, experts advantages of professionals in various disciplines and make supervision work more targeted and effective.

Perfect teaching supervision system

Further clarify the responsibilities, rights and interests of supervisory staff, improve status and role of teaching supervision in quality monitoring system, and strengthen its supervision function (see Figure 1).

\section{"Integration" of supervision and service}

"Guiding" is the key content of the teaching work, and "supervision" is for more effective guiding. Supplemented by "supervision", oriented by "guiding", "guiding" will be in concrete place, and "supervision" will be implemented well and deeply. Supervisory staff should supervise teachers' work, to learn and master their shortcomings, to help them solve the problems in education, reform teaching methods and means and improve the teaching skills; supervisory staff should explore the potential of teachers, to help them sum up experience, and develop personalized style of teaching. Simultaneously, school-level and college-level management departments shall regularly organize supervision meetings, collect advice, sort out information, solve the existing problems in supervision work, and help supervisors improve efficiency and supervision level, to better serve the teaching work.

\section{Construct “3-supervision” supervision content system}

Teaching supervision content includes teaching supervision, learning supervision and management supervision. Teaching supervision is aimed at teaching process, focused on by most colleges, while learning supervision and management supervision have not been reflected. Learning supervision is to check and guide students' learning process and activities. Students are carrier to reflect the quality of teaching, and is an important object of teaching supervision. Content of learning supervision includes students' "3 views", ideological and political consciousness, learning consciousness and other physical and moral aspects; through learning supervision, promote students' self-control, self-management, and improve their overall quality. Management supervision means guiding and checking teaching management staff. On the one hand, the school should be check and evaluate the work of teaching management staff, to ensure that teaching management departments fulfill management responsibilities to the greatest degree; on the other hand, the school should provide systematic teaching management knowledge training for teaching management staff, to improve teaching management quality and capacity. It can be seen that only "3-supervision" supervision content system can truly comprehensively and efficiently exert role of teaching supervision.

\section{Strengthen supervision team professionalization construction}

Foreign countries always attach importance to the overall quality of supervisory staff. Supervisory staff should be proficient in educational theory, educational management and teaching practices. To build a supervision team including part-time and full-time staff, with reasonable age structure and good quality is required by higher education reform and development, and is also an inevitable requirement for colleges to improve the teaching quality. Colleges should strengthen professional construction and structure optimization of supervision team, require supervisors to have professional knowledge, professional skills and professional ethics, establish effective teaching supervisory staff training mechanisms, clarify responsibilities and powers, strengthen theory technology research, to improve the level of supervision

In summary, as an effective means of teaching quality assurance, teaching supervision plays its active role in developing educational decision-making, standardizing teaching management and improving teaching quality. Whether teaching supervision system can be successfully constructed and operated well or not critically depends on whether colleges have a high-quality supervision team. 


\section{Acknowledgments}

This paper is one of the research results of 2014 Hebei United University Education Reform Major Project, which name is Research and Practice of Local College Education Supervision Team Professional Construction, Project No. z1320-20.

\section{References}

[1] Li Hui. On Current College Teaching Supervision work. Journal of Chifeng College, 2009 (6): 122-124.

[2] Liu Aiqun, Liu YuHong, Ma Jigang Thoughts on Improving the Effectiveness of College Teaching Supervision Work. Kiamusze University Social Science Journal, 2010 (2): 108-109.

[3] Zhang Xuan. Problems and Thoughts on College Teaching Supervision Work. Journal of Huizhou College, 2010 (2): 106-108.

[4] Ling Feifei. Problems and Solutions of College Teaching Supervision System. 2009,26 (11): 100-102 